\title{
Recurrent Anterior Urethral Stricture: Challenges and Solutions
}

\author{
J Patrick Mershon (D) \\ Nima Baradaran \\ The Ohio State University Department \\ of Urology, Columbus, OH, USA
}

Correspondence: Nima Baradaran Department of Urology, The Ohio State University Wexner Medical Center, 915 Olentangy River Road, Columbus, $\mathrm{OH}$, 43212, USA

Tel $+|-6| 4-293-8 \mid 55$

Fax + I-6I4-366-6966

Email Nima.Baradaran@osumc.edu

\begin{abstract}
Recurrent male anterior urethral stricture disease is a complex surgical challenge that should be managed by reconstructive urologists with experience in stricture management. Diagnosis of recurrence requires both anatomic narrowing and patient symptoms identified on validated questionnaires, with limited role for intervention in asymptomatic treatment "failures". Endoscopic management has a very specific role in recurrence, and the choice of technique for urethroplasty depends on pre-operative urethrography and cystoscopy. Surgical success depends on addressing patient concerns, complete stricture excision, tissue quality optimization, and the use of multi-stage repair when indicated. Augmentation with genital skin flaps and/or grafts is often required, with buccal mucosa as the ideal graft source if local tissue is compromised. Salvage options including urinary diversion and perineal urethrostomy must also be considered in debilitated patients with severe disease or repeated treatment failures. Unique patient populations including patients with hypospadias and lichen sclerosis are among the highest risk for repeated recurrence and require special care in surgical technique, graft selection, and post-operative management.
\end{abstract}

Keywords: salvage urethroplasty, revision urethroplasty, lichen sclerosis, hypospadias

\section{Introduction}

Male urethral stricture disease (USD) is a complex and heterogenous clinical entity with a wide variety of etiologies and presentations. It is an often underappreciated cause of patient morbidity and healthcare expenditure, with an estimated incidence as high as 0.6 to $1.2 \%$ even in developed countries. ${ }^{1-3}$ Impacts on patients include lower urinary tract symptoms (LUTS) including dysuria, recurrent urinary tract infections (UTI), and in some cases upper tract degeneration and even renal failure. ${ }^{4,5}$ The etiology of USD varies across care settings, with untreated sexually transmitted infection more common in low- and middle-income countries, and iatrogenic USD from instrumentation or chronic catheterization rising in incidence, particularly in developed countries. ${ }^{3,6-8}$ External trauma to the perineum or pelvis is another important cause, as is radiation to the prostate or pelvic structures. ${ }^{3}$

Management options for primary USD include simple dilation, endoscopic treatments including direct vision internal urethrotomy (DVIU) or urethral dilation and open repair or urethroplasty. ${ }^{5,6,8}$ Depending on the etiology and severity of the stricture and the choice of initial management, success rates after primary intervention can range widely, from approximately $20-90 \%$ (See Table 1). ${ }^{3,9-11}$ However, for many patients USD recurrence is a likely outcome of the initial procedure, particularly with endoscopic management options. Recurrence rates 
Table I Recurrence Rates After Initial Repair Based on Anatomic Location and Surgical Technique

\begin{tabular}{|l|l|l|}
\hline Stricture Location & $\begin{array}{l}\text { Surgical } \\
\text { Technique }\end{array}$ & $\begin{array}{l}\text { Recurrence } \\
\text { Rate }\end{array}$ \\
\hline Bulbar & EPA $^{\mathrm{a}}$ & $5-20 \%^{5,6,11,19}$ \\
& $\mathrm{BMG}^{\mathrm{b}}$ & $12-19 \%^{20-22}$ \\
& Penile skin graft & $16-18 \%^{22}$ \\
\hline Penile & Multiple & $16-27 \%^{5,23,24}$ \\
& BMG & $7-30 \%^{24,25}$ \\
& Skin flap & $12-14 \%^{25,26}$ \\
\hline \multirow{2}{*}{ Meatal/Fossa Navicularis } & Meatotomy & $2-15 \%^{27-29}$ \\
& BMG & $7-44 \%^{29-31}$ \\
& Skin flap & $4-17 \%^{29,31}$ \\
\hline
\end{tabular}

Notes: Excision and primary anastomosis ${ }^{\mathrm{a}}$. Buccal mucosal graft ${ }^{\mathrm{b}}$.

following endoscopic treatments range between 23 and $92 \%,{ }^{5,12}$ and are even higher with multiple endoscopic procedures, eventually approaching 100\%. ${ }^{6,13,14}$ Across all studies, risk factors for USD recurrence include stricture length, smoking, obesity, diabetes mellitus, congenital malformation such as hypospadias, presence of chronic inflammatory conditions such as lichen sclerosus (LS), and previous attempts at management, particularly with augmentation or substitution urethroplasty. ${ }^{5,15-18}$ Particularly in patients at elevated risk of recurrence, these data support close follow-up and evaluation for possible treatment failure after primary urethroplasty.

Current literature on USD management suffers from limited quality of data and a diverse patient population. Very few randomized controlled trials exist, and there remain difficulties in assigning patients to meaningful categories given the immense variability in previous management, size and location of stricture, and in the definitions of treatment "success". 6 Recurrent USD offers particular challenges in both diagnosis and in choosing the appropriate therapeutic intervention. Much of the management of recurrent USD is still currently guided by expert opinion given the limitations of current literature. ${ }^{5}$ However, this review attempts to summarize the contemporary data available and to discuss the identification, evaluation, and management of recurrent USD.

\section{Definition of Recurrence}

The definition of USD recurrence is still relatively variable across the existing literature. The "classic" and most commonly used definition is the need for operative reintervention $^{4,15,32}$ which has the benefit of being easily measurable but fails to capture the complexity of recurrence. $^{5,33}$ Because many patients with recurrent USD and severe symptoms may elect to avoid surgery for a variety of reasons, this definition is at best a subjective measure of treatment failure. ${ }^{34}$ Due to these limitations there continues to be a need for a more useful and accurate definition of treatment failure and/or USD recurrence that encompasses the patient experience as well as physical changes within the urethra.

\section{Anatomic Failure}

USD is fundamentally a narrowing of the urethral lumen from its average physiologic diameter of approximately 24-26 French (Fr). Recurrent narrowing after intervention is thus a reasonable definition of USD recurrence. Various cutoff points for defining recurrence have been proposed, including $9,{ }^{35} 14,{ }^{36}$ and $16 \mathrm{Fr}^{33}$ Primarily these values are designed to pre-empt the recurrence of obstructive voiding symptoms; historical estimates place the diameter at which obstructive symptoms occur at approximately $10 \mathrm{Fr}$, though this number has never been truly validated. ${ }^{37}$ Urethral calibration with sounds is theoretically an appropriate method for evaluating stricture diameter, but the possibility of unintentional trauma precludes its widespread use. The gold standard definition for anatomic USD recurrence is most commonly the failure to pass a cystoscope (typically 16-17 French) through the stricture without force. ${ }^{33,36,38}$ This definition has the advantage of being a clear binary without any differences in measurement accuracy inherent in the various imaging tools and without the high risk for urethral trauma introduced with calibration using sounds. The disadvantages are the need for secondary imaging after cystoscopy to identify the proximal extent of the stricture if the cystoscope cannot pass through the narrowed lumen as well as cost and patient discomfort.

Imaging can be another valuable tool in identifying and assessing treatment failure. Classically retrograde urethrography (RUG) has a sensitivity of $75-100 \%$ in identifying primary USD. ${ }^{36,39}$ Some studies have questioned the value of RUG over other screening tools in identifying recurrence, ${ }^{35}$ but it is still common practice both as a primary screening tool and as the initial test after symptom-based screening identifies potential recurrence. ${ }^{32}$ Adjunct voiding cystourethrogram is similarly commonly used for screening, with particular value in assessing posterior USD. ${ }^{39}$ These techniques have the primary advantage of allowing the clinician to identify asymptomatic USD, and to 


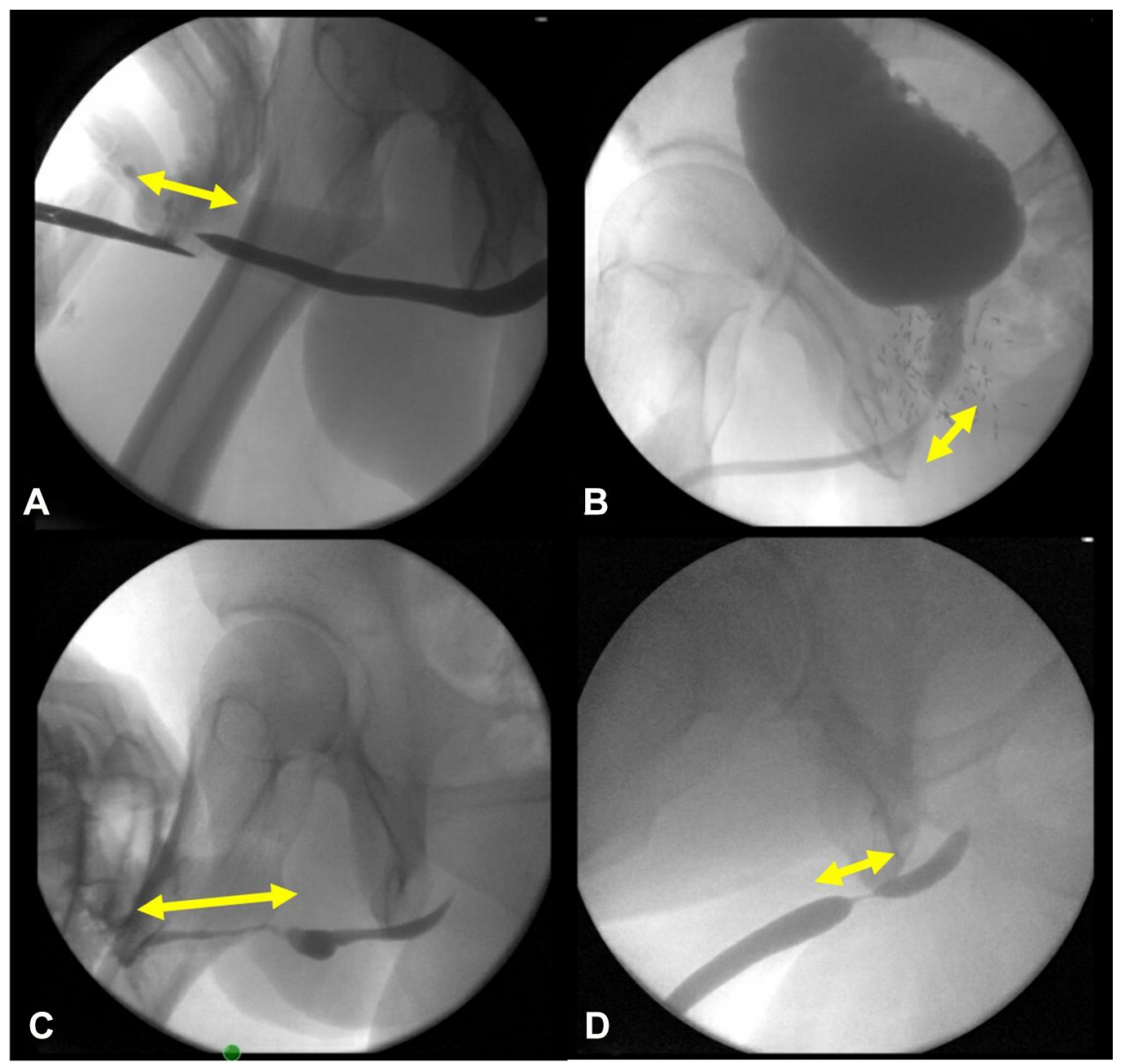

Figure I Urethrogram images of four representative patients with USD (arrows identifying strictured areas). (A) 46-year-old male with $3 \mathrm{~cm}$ meatal fossa stricture after failed meatoplasty. (B) 67-year-old male with recurrent bulbo-membranous stricture after brachytherapy for prostate cancer. (C) 24-year-old male with penile stricture and urethral diverticulum in the setting of previous penoscrotal hypospadias and multiple reconstruction attempts. (D) 39-year-old male with rapid recurrence after EPA (not suitable for DVIU).

evaluate the entire length of the urethra simultaneously in order to plan a potential revision operation (Figure 1).

Magnetic resonance imaging (MRI) evaluation of USD is rarely employed given the expense of this diagnostic tool and the widely available and less expensive alternatives. It is primarily used in oncologic USD to evaluate surrounding disease, and may be useful in complex traumatic USD with large urethral gaps or obliteration. ${ }^{6}$ Computed tomography (CT) may be useful in evaluation of fistulae resulting from USD, but is rarely employed for primary evaluation of the urethra. ${ }^{6}$

Cystoscopic and imaging definitions of anatomic failure offer a valuable tool to reconstructive urologists attempting to measure their surgical success and to compare the failure rates of different surgical techniques. However, there remains the question of how to interpret the high rate of asymptomatic "failures", estimated to be up to $35 \%$ of USD recurrences. ${ }^{38}$ Kessler et al found that $80 \%$ of the patients they defined as anatomic failures were "satisfied" or "highly satisfied" with their surgical outcome. ${ }^{40}$ In addition, in the setting of high patient-reported success rates, using cystoscopy as a screening tool in asymptomatic patients may subject up to $84 \%$ of men to an unnecessary procedure, increasing the risk of UTI and other complications of cystoscopy in addition to patient dissatisfaction. ${ }^{32}$

\section{Functional Failure}

The need for re-intervention should be based on the presence of patient symptoms in the setting of radiologic or cystoscopic abnormalities. ${ }^{10}$ There have been multiple attempts to create a definition for treatment failure in terms of patient experience, with the earliest attempts using pre-existing tools to evaluate urinary symptoms after USD intervention. The American Urological Association (AUA) Symptom Index has been used in several studies, with patient-reported failure to improve after intervention showing good sensitivity to identify 
recurrent urethral narrowing. ${ }^{4,13,41}$ Similarly, the International Prostate Symptom Score has been used with varying degrees of success to screen for recurrence. ${ }^{33,42}$ There have been multiple attempts to form a more systematic questionnaire targeted to USD-related obstructive voiding symptoms, most notably the Patient-Reported Outcome Measure (PROM) generated by Kessler et al in 2002 and the Urethral Stricture Surgery PROM generated by Jackson et al in 2011. ${ }^{40,43}$ Both of these showed robust improvements in patient symptom scores after successful urethroplasty and were effective in identifying symptomatic treatment failures. ${ }^{44}$ Importantly, symptomatic failures without imaging or cystoscopic evidence of recurrence should always undergo evaluation for bladder pathology that can mimic USD.

However, it is also important to note that some failures of urethroplasty can occur in the absence of obstructive voiding symptoms: reduced sexual function, pain, poor cosmesis, and altered voiding quality are also important indicators of a treatment failure. ${ }^{44}$ These quality of life measures often have an equal or larger role than objective voiding dysfunction in determining patient satisfaction with a surgical procedure. ${ }^{45}$ There is currently an ongoing attempt to devise a comprehensive PROM specific to USD that encompasses all of these potential factors; the patientcentered outcome measure in development by Breyer et al that is currently being validated for use, called the Urethral Stricture Symptoms and Impact Measure (USSIM). ${ }^{46}$ This questionnaire was generated through an intense process of patient and surgeon interviews and may offer the next step in systematically assessing patient factors relevant to treatment success or failure.

The importance of a multifactorial approach to management is evident in the recent randomized control trial by Goulao et al comparing DVIU with open urethroplasty in recurrent bulbar USD. ${ }^{47}$ Open surgery resulted in fewer recurrences and interventions (consistent with previous data), but showed no differences in the profile of a validated PROM between the two randomized groups over 24 months. Both subjective and objective measures are clearly needed to meaningfully define treatment success or failure in recurrent USD.

\section{Management Approach}

The management of recurrent USD is dependent on multiple variables, including the location and severity of the stricture, the age and goals of the patient, and the initial surgical technique. As discussed above, for nearly all recurrences after DVIU or dilation, the most effective method is to proceed to open urethroplasty, given the poor results of continued endoscopic management. ${ }^{5,6,12,13}$
This is also in line with current American Urologic Association (AUA) guidelines on male USD. ${ }^{48}$ Once the decision is made to proceed to urethroplasty, the details of the recommended surgical repair will depend on the location of the stricture, quality of surrounding tissue, underlying pathology and surgeon preference, though some general principles will be discussed below. Any repeat intervention should also be delayed to allow for full maturation of the stricture, a process that may take up to three months after surgery or recent cystoscopic passage. ${ }^{6}$

It is important to note that there may be different categories of recurrence after primary urethroplasty. Kahokehr et al identified two separate types of USD recurrence after bulbar urethroplasty; one focal and annular and the other a stricture of the entire operative area, theorized to be a result of diffuse ischemia (Figure 1D). ${ }^{19}$ The authors demonstrated good success $(\sim 78 \%)$ with a single endoscopic procedure in recurrent patients with focal USD, with most failures being in patients with longer, more occlusive pathology. Based on these results they recommended DVIU or dilation only for these focal strictures and reserving revision urethroplasty for longer, more involved recurrences. In general, the literature supports this management strategy, with reported success rates of DVIU after urethroplasty higher than in primary USD and ranging from $34 \%$ to $60.5 \%{ }^{11,21,49,50}$ The viability of endoscopic treatment for recurrent bulbar USD in particular is also supported by the OPEN trial with equivalent PROM measures after randomization to DVIU or urethroplasty. ${ }^{47}$ Based on these data, it seems likely that many patients with recurrence after urethroplasty will benefit from endoscopic management as an initial attempt, particularly if the nature and extent of the stricture is assessed with imaging and/or cystoscopy and appears amenable to DVIU. Notably, several authors in the field recommend against DVIU for primary or recurrent USD in the penile urethra due to the increased likelihood of spongiofibrosis and thus recurrence. ${ }^{5,48}$ Therefore, recurrences that are short, annular or "veil-like," and located in the bulbar or posterior urethra are the best candidates for attempted endoscopic re-intervention.

After a failed endoscopic treatment or if a longer and more complex recurrence is identified, open repair is the best option. However, it is critical to assess the stricture in its entirety as well as to identify the operative details of the initial urethroplasty in order to optimize the success of the second procedure. There are several general concepts that are important to apply to revision urethroplasties (Table 2). Most importantly, the success of revision depends on the vascular supply to the affected area, which was likely compromised by the initial 
Table 2 Key Surgical Concepts in Revision Urethroplasty

I. Optimize remaining vascular supply and avoid further compromise

2. Avoid transecting techniques and electrocautery

3. Excision of all fibrosis prior to repair

4. Fully mobilize urethra and avoid tension on closure

5. Thorough operative planning with multiple "bail-out" options

surgery, and every attempt should be made to avoid further compromise to the vascular bed. ${ }^{10,51}$ This is accomplished with meticulous dissection in the strictured area and delicate tissue handling with careful attention given to minimizing cautery wherever possible. ${ }^{23,52}$ Avoiding the use of transecting techniques can also help to optimize the quality of the vascular bed after revision, though in densely fibrotic and circumferential USD this is often unavoidable. ${ }^{51}$

Other important concepts include the benefit of excising any observed spongiofibrosis, particularly in the setting of traumatic USD. ${ }^{19,53}$ This avoids the poor tissue healing characteristic of scar tissue, reducing the size and density of any reactive urethral narrowing during post-operative healing. ${ }^{51}$ Urethral mobility is also often reduced in the setting of prior operation; most experts recommend minimizing tension at the new repair site by fully mobilizing the proximal and distal urethral segments, both for anastomotic and augmentation techniques. ${ }^{2,48,54}$ To minimize blood supply disruption, ventral attachments can be disrupted while preserving the dorsal vascular bed and corporal attachments. ${ }^{53}$ This mobilization will avoid tension on the repair and may help to minimize trauma during erection and help to avoid resulting disruption or fibrosis. ${ }^{2}$ In addition, one must always be aware that revision urethroplasty may be complicated by reduced options for graft sources, necessitating greater creativity and more thorough preoperative planning. ${ }^{4}$ Alternative options for graft harvest sites are discussed in a separate section below.

\section{Meatus/Fossa Navicularis}

The etiology and pathology of distal penile USD differs from those in other areas of the pendulous urethra, with iatrogenic causes and LS (discussed below) predominating (Figure 1A). Management is also different, with DVIU quite difficult or impossible due to the anatomic location and the reduced vascularity resulting from a deficiency of spongiosum tissue. ${ }^{29}$ For short fossa navicularis or meatal USD, meatotomy is classically performed with good success, though the recurrence rates are significantly higher than with true meatoplasty. ${ }^{27}$ Due to this high failure rate, meatotomy is not considered appropriate initial management for recurrent USD except in special circumstances. For recurrent meatal or fossa navicularis USD flap urethroplasty (most commonly fasciocutaneous ventral transverse island skin flap) has a longstanding record of success and is an excellent option if adequate source tissue is available. $^{29,31}$ If local flaps have been exhausted or are contraindicated due to LS, buccal mucosal graft (BMG) can be used in these distal areas though more complex techniques are required, including double grafting with or without the creation of glans wings to enhance vascular support to the new grafts. $^{28,55,56}$

\section{Penile Urethra}

Penile USD often requires the most complex and difficult of repairs because of poor vascularization and trends towards longer, more fibrotic strictures that are also more likely to recur (Figure 1C). ${ }^{3}$ Most commonly, these revisions are approached with one-stage substitution or augmentation urethroplasty or two-stage repair, with BMG as the ideal graft tissue source. ${ }^{10}$ Success rates are very mixed, with reports of $18-20 \%{ }^{49}$ in some groups and $68-71 \%{ }^{57,58}$ in others. The extreme variability of penile USD and the high degree of overlap with hypospadias and LS makes it difficult to accurately compare techniques or success rates in this population. In general, the literature supports complex single or multistage repair with BMG as the best option for these often-complicated recurrent USD. If onlay grafting is performed, it may be reasonable to attempt either a different technique entirely or to change the location of the graft onlay (ie, dorsal when the primary repair was ventral). ${ }^{51}$ Notably, the type of previous repair seems to influence success rates of revision urethroplasty, with primary BMG augmentation appearing to offer the best chances of a successful revision procedure. ${ }^{59}$

In the most complex of penile USD, vascularized pedicle fasciocutaneous flaps offer another management option with good durability and success rates, particularly in the setting of advanced scarring and poor vascularity such as occurs with heavily operated tissue or after radiation. ${ }^{4}$ However, the surgical challenge of this technique is considered to be much higher with longer procedural times and increased complications including skin necrosis and fistula formation. ${ }^{2}$ Common sources for flaps are penile shaft skin and preputial skin (prepared and transplanted with underlying dartos fascia), though depilated scrotal skin can be used in particularly complex or recurrent USD. ${ }^{6}$ Tubularized flaps (or grafts) should be avoided if at all possible due to the higher risk of re-stenosis when compared to onlay repair. ${ }^{48}$

Long-term success rates with fasciocutaneous flaps are relatively similar to grafting at $85-95 \%$ in high-volume 
centers, ${ }^{3,4,60}$ though some studies report lower success rates below $80 \%{ }^{10,49,61}$ and controversy still exists over the true comparison of these options with proponents on both sides. Due to the steep learning curve, questionably lower success rates and higher complication rates, this technique is much less common than it has been historically. ${ }^{62}$ In many complex patients, local tissue including foreskin and penile skin have been exhausted or are of poor quality, limiting the applicability of flap techniques. In addition, as this technique has lost popularity there is a global lack of training for contemporary reconstructive urologists interested in learning classic techniques.

\section{Bulbar Urethra}

In bulbar USD, the success rates tend to be higher due to the more favorable nature of this urethral territory with good vascular supply and easy mobilization of tissue
(Figure 1B). This area also has the widest variety of management options available, with excision and primary anastomosis and substitution urethroplasty (usually with BMG) as the most commonly reported. ${ }^{51,63}$ Using either technique, the success rates in recurrent USD are equivalent and remain high, reported as an $85-95 \%$ success rate in most studies. ${ }^{53,57,58,63}$ A recent meta-analysis by Jasionowska (2019) reported success rates of $58-100 \%$ for recurrent bulbar USD using both EPA and BMG techniques. ${ }^{10}$

\section{Panurethral Stricture}

Panurethral stricture management requires more surgical flexibility and comfort with a wide range of techniques. Kulkarni et al recommend a single stage, one-sided dissection with BMG and had excellent success rates of $61.5 \%$ in revision urethroplasties. $^{23}$ These single-stage techniques are likely possible in selected patients with a reasonable urethral caliber, no

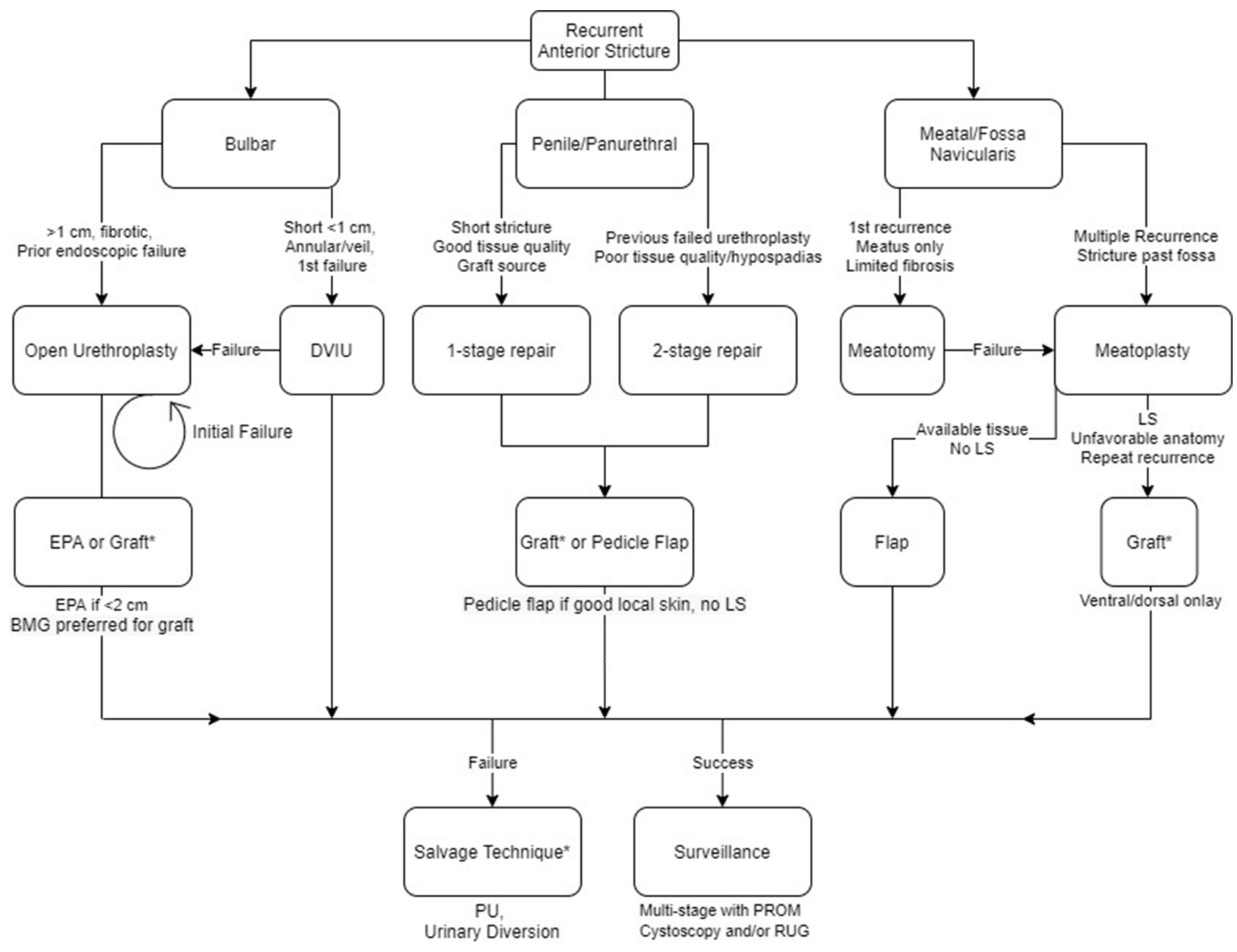

Figure 2 The authors' treatment algorithm for recurrent stricture based on anatomic location and other characteristics.

Abbreviations: BMG, buccal mucosal graft; PU, perineal urethrostomy; PROM, patient-reported outcome measures; RU, retrograde urethrogram; LS, lichen sclerosus; EPA, excision and primary anastomosis; DVIU, direct vision internal urethrotomy. 
areas of total obliteration, and a healthy-appearing urethral plate. ${ }^{64}$ However, more commonly performed is a two-stage urethroplasty given the extent of diseased urethra and the likelihood of recurrence with less definitive management ${ }^{65,66}$ Occasionally more aggressive options are warranted, with some authors recommending mesh grafting from the inner thigh. ${ }^{58}$ Overall results continue to be poor even after complex multi-staged repair in these patients, with the location, extent of disease, and likely association with chronic inflammation continuing to elevate the risk of recurrence. ${ }^{5,15}$ These patients will often end up resorting to salvage options, discussed below.

Short bulbar strictures are often the least likely to recur and the most responsive to endoscopic or non-grafted urethroplasty. Longer, more complex USD involving the penile urethra is more likely to recur and responds better to augmented or two-stage procedures. However, there exists no level one evidence to support these management choices given the current limitations of the literature. The optimal operative course, particularly for non-standard patients, is still primarily based on surgeon experience and expert opinion. Further studies, and particularly more rigorous definitions of stricture classification and success, are needed to determine the truly optimal management strategy for certain USD cases. Nonetheless, certain authors have tried to systematize the expert recommendations that exist within the field, with algorithms designed to assist reconstructive decisions for USD; we present an updated, comprehensive algorithm (Figure 2).

\section{Alternative Graft Options}

There are situations in which an augmented graft technique is ideal for the management of a particular patient and the most commonly utilized graft source - BMG - is unavailable, either due to previous harvesting or due to damage from smoking or disease. In these situations, there are multiple alternative graft sources that can be considered depending on the specific clinical situation. Important to note in cases where BMG has been exhausted due to prior attempts but the oral mucosa is undamaged by smoking or inflammatory disease, lingual grafts are an excellent option and have shown equivalent success rates to $\mathrm{BMG}$ across multiple studies. ${ }^{67}$ Extragenital skin is often the first choice for longer, more complicated USD when BMG is unavailable. Postauricular ${ }^{68,69}$ and abdominal wall ${ }^{70}$ skin have shown excellent results with large harvests and minimal morbidity, though LS involvement can lower success rates significantly. ${ }^{71}$ In order to avoid potential complications of hair growth within the neo-urethra, split-thickness skin grafting can be used which has the added advantage of reduced harvest site scarring. ${ }^{6,72}$

In extreme cases, there are other sources of graft material that can be considered. Bladder mucosa has many favorable properties including inherent tolerance of urine exposure and large graft segment harvest without significant harvest site morbidity. ${ }^{73,74}$ However, it classically requires open surgical harvest and suffers from higherthan-average complication rates, making it a last resort typically reserved for severe proximal hypospadias and other major congenital malformations. ${ }^{67,75}$ Colonic and rectal mucosa, harvested after either sigmoid resection or transanal endoscopic mucosal resection, offers another excellent graft choice for long, complex USD that has failed previous management attempts with long-term success rates comparable to other graft sources at $\sim 85 \%{ }^{76,77}$

In the future, tissue engineering will likely offer custom graft material without the morbidity of tissue harvest, though these techniques remain experimental for the time being. One experimental option that shows promise is liquified $\mathrm{BMG}$ which can be injected into urethrotomy sites. This injection decreases recurrence rates after DVIU in animal models and has been trialed in humans with promising but mixed results. ${ }^{78,79}$ Also available are solid tissue constructs or scaffolds, potentially seeded with autologous cells, designed to simulate native urethral mucosa ${ }^{67}$ These grafts can be constructed from decellularized natural scaffolds (generally bladder, small intestine, or dermis) or fully synthetic polymers and then seeded with cells harvested from bladder biopsy, voided urine, or other sources. ${ }^{80}$ Decellularized scaffolds work well for short strictures with fewer side effects and more reliable construction, but cellularized matrices offer better uptake and reduced rates of stricture, at least in animal models. ${ }^{67,80,81}$ To date there are no large human trials with any of these novel grafts and widespread adoption is likely still many years away given the regulatory, financial and engineering challenges associated with this new technology.

\section{Salvage Options}

There are occasional situations in which revision urethroplasty or DVIU is no longer a viable option. This occurs most commonly with USD that has failed multiple operative attempts at repair, and the resulting fibrosis renders reoperation technically impractical or impossible. In addition, changes in patient status or goals of care may render the indicated operation inappropriate for a particular 
patient. In these cases, special consideration must be given to palliative DVIU, perineal urethrostomy, or urinary diversion, each of which plays a role in certain patient groups.

Palliative DVIU may be undertaken in patients who are medically unfit for definitive urethroplasty but who still have smaller, more manageable USD that can be temporized with an endoscopic procedure. ${ }^{82,83}$ These patients will by definition need a series of procedures in order to maintain urethral patency but may enjoy an improved quality of life in periods between recurrences. Another temporizing option is self-dilation with clean intermittent catheterization, with or without intraurethral steroid administration. This has high success rates over the short term, particularly in LS-related USD, and can avoid the need for surgical intervention. ${ }^{84}$

Perineal urethrostomy (PU) is another salvage option in patients with complicated anterior urethral or panurethral disease. This is occasionally performed as the first stage of a multi-stage surgery, but can also be used as definitive treatment for complex repairs. Several case studies have high proportions of patients that defer the second stage of a multistage urethroplasty due to satisfaction with PU. In the setting of definitive repair, satisfactions rates with PU are high at approximately $97-100 \%{ }^{85,86}$ with improved urinary function and no changes in erectile function. ${ }^{42}$ In addition, this operation has high success rates of $70-95 \%$, with revision rates the same or lower than complex anterior reconstructions. ${ }^{42,86}$ It can be performed as an outpatient procedure, with more rapid return to activities of daily living, catheter-free voiding, and erectile function. ${ }^{87}$ Finally, PU maintains the distal urethra available for future reconstruction if patient goals change with time. Notably, in cases of pelvic trauma with damage to the perineum and the bulbar urethra success rates of $\mathrm{PU}$ may be lower and patients should be carefully selected to maximize success rates. ${ }^{85}$

Abandonment of the urethra and urinary diversion should only be considered as a last resort when all other methods, including consideration of PU, have failed. ${ }^{5,21}$ This is more likely to occur with complex posterior USD, or with heavily irradiated or fibrotic tissue that has already undergone repeated interventions leading to a devastated urethra. In these settings, Mitrofanoff appendico-vesicostomy is the most commonly used surgical option, and if necessary is likely to greatly improve patient quality of life after successful diversion. However, if a patient wishes to pursue more physiologic voiding in the setting of devastated urethra, there are case reports of intestinal and appendiceal free flaps used to repair particularly complex posterior USD in carefully selected patients. ${ }^{88,89}$ These approaches require microvascular anastomotic techniques to support the flap, staged reconstruction, and particular surgeon expertise, often in collaboration with other specialized surgeons including plastic surgery.

\section{Special Cases}

In addition to failed repairs, there are several situations that require specialized training in order to optimize management. These include hypospadias-related anterior USD and LS-related USD.

\section{Hypospadias}

Initial surgical management of hypospadias in children is often complicated by development of USD, with rates ranging from $6 \%$ to $12 \%$ that may require repeated interventions as an adult. ${ }^{17,52,90}$ The factors influencing the high rate of recurrent USD in this patient population include the initially poor tissue quality as well as the reduced vascularity of the malformed and surgically altered distal urethra and corpus spongiosum. ${ }^{91}$ The lack of normal spongiosum may predispose the urethra to trauma during voiding, erection and sexual activity, leading to recurrent fibrosis and stricture. ${ }^{92}$

These factors also complicate any operation aiming to address recurrent USD. In a series of 60 adult patients undergoing revision hypospadias repair, Barbagli et al achieved a $75 \%$ success rate using either one-stage or multi-stage urethroplasty, primarily with $\mathrm{BMG}^{92}$ In a larger retrospective review of revision hypospadias procedures, Barbagli et al found success rates of $90.4 \%$ with single-stage procedures and $83.9 \%$ in staged repairs. ${ }^{93}$ These results are consistent with other large cohorts in the literature, which tend to have relatively good success rates between $84.9 \%$ and $90 \%$ in high-volume centers. ${ }^{32,91}$ For a long meatal/fossa navicularis stricture after failed hypospadias repair, a two-stage reconstruction with BMG and concomitant repair of any residual chordee is the preferred treatment option. Excision and primary anastomosis, while generally not recommended in the penile urethra due to chordee risk, is contraindicated in patients with a history of hypospadias repair; these patients lack vascular anastomoses with the corpora cavernosum and may lose all perfusion to the distal urethra after transection. ${ }^{2}$ Synchronous USD in the bulbar urethra can 


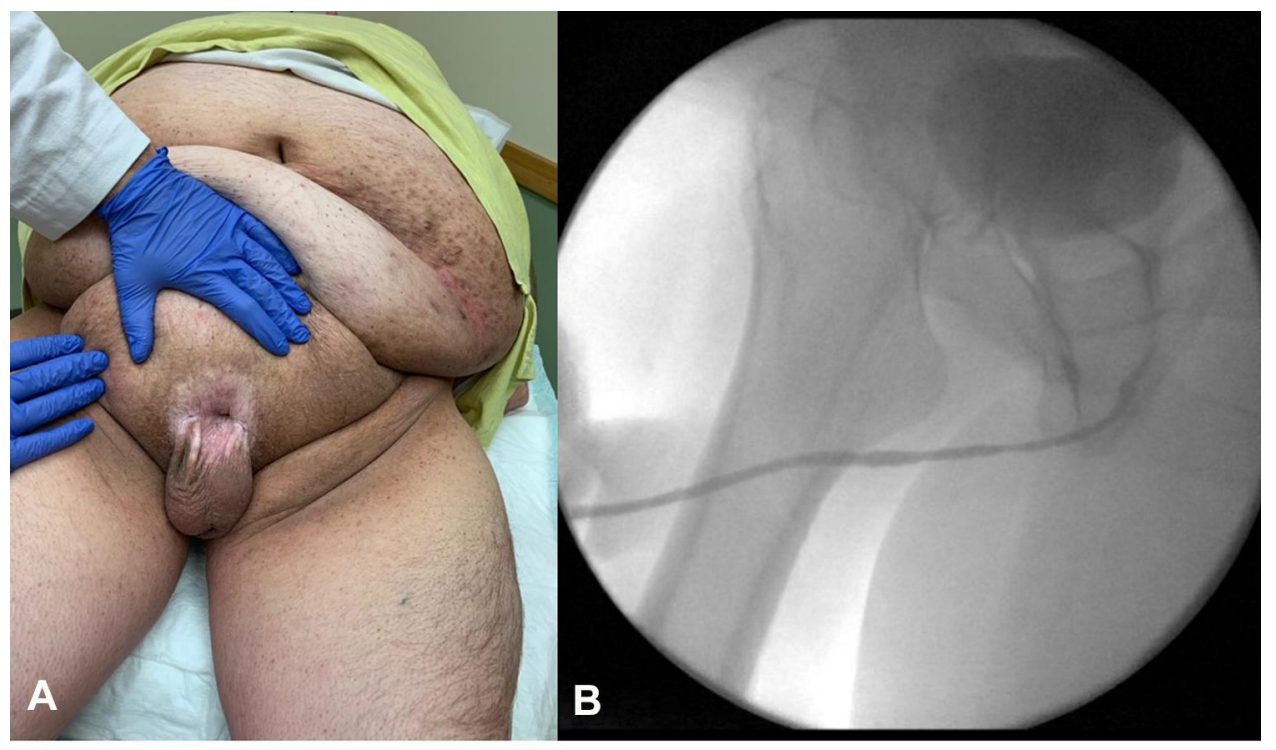

Figure 3 (A) 40-year-old male patient with severe LS affecting the peri-genital skin in addition to the meatus. Photo courtesy of Dr. Cooper Benson. (B) Retrograde urethrogram of a $5 \mathrm{I}$-year-old male with panurethral stricture as a result of LS involvement.

be addressed with a variety of augmentation techniques, as discussed above. In particularly severe cases or after multiple unsuccessful procedures, salvage options are more often required in hypospadias patients. Perineal urethrostomy is an excellent choice in these patients and allows diversion away from poor-quality and over-operated distal urethra. $^{86,94}$

\section{Lichen Sclerosus}

LS is a chronic inflammatory disorder of genital skin of unclear etiology that is highly associated with USD, with $20 \%$ of patients having urethral involvement (Figure 3A). ${ }^{95}$ Notably, the disease progresses from the meatus proximally and thus always has penile involvement, though it can cause pan-urethral stricture (Figure $3 \mathrm{~B}$ ) and in fact is the leading cause of this severe form of USD. ${ }^{18,23}$ Historically, recurrence rates ranged from $50 \%$ to $100 \%$ after primary urethroplasty because of the use of genital skin flaps or grafts that were prone to involvement with $\mathrm{LS},{ }^{96}$ prompting strong recommendations against continuing this practice during reconstruction. ${ }^{4}$ With more modern techniques recurrence rates are still high; Meeks et al found that LS increased the rate of recurrence after distal urethroplasty from $7.5 \%$ to $20.5 \%$ even after all involved tissue was excised. ${ }^{31}$ Similar recurrence rates are reported from other groups, ranging from $18 \%$ to $27 \%^{23,87,97,98}$

Management of recurrent USD is difficult and technically complex. For both primary and recurrent USD with
LS involvement, multi-stage urethroplasty is generally preferred. ${ }^{3,91}$ Grafts cannot come from genital or extragenital skin and BMG is the most common alternative. Kulkarni et al recommend a single endoscopic treatment for short, focal stricture recurrences and then ventral patch with BMG for longer strictures or those that fail endoscopic management. ${ }^{23}$ In light of the inflammatory nature of LS and high recurrence rates, some experts recommend excision of the entire segment of involved urethra, though this can limit the caliber of the final repair and the necessity of this step is currently debated in the literature. ${ }^{18,31}$ Salvage PU is an excellent choice in LS patients and should also be considered as part of the staged procedure for LS-related recurrent USD; diversion of urine away from LS-involved skin has resulted in desiccation and occasional resolution of LS. ${ }^{85-87}$ Shortor long-term diversion with PU also maintains the distal urethra for use in future consideration of formal reconstruction.

\section{Conclusions}

Identifying treatment failure after initial USD surgery requires balancing both anatomic and functional failure. Leading authors in the field specifically recommend a twotiered approach to management, with attempts to target functional failures for re-treatment, and to monitor for anatomic recurrence to evaluate and compare surgical techniques. $^{33,44}$ It is critical to use disease-specific PROMs and to thoroughly evaluate possible recurrence 
with urethrography and cystoscopy in order to appropriately plan for the management of any recurrent USD.

There are very few universal principles to apply to the management of recurrent anterior USD (Table 2), and the surgeon must be both prepared and flexible in order to maximize their chances of success. Meticulous preoperative planning with imaging and/or cystoscopy, and patient history is critical, as is the utilization of techniques most suited to the anatomic location and severity of the disease. It is important to plan for and discuss multiple graft sources as well as salvage options in certain patients. Highly complex pan-urethral USD should primarily be managed in highvolume centers with expertise due to the high rates of failure and the limited repair options available.

In this particular patient population, lifelong postoperative surveillance is appropriate. ${ }^{5}$ Increased frequency and attention to avoid attrition is even more important in patients with LS given the extremely high rates of recurrence as well as the risk of malignancy. ${ }^{99}$

\section{Disclosure}

The authors report no conflicts of interest in this work.

\section{References}

1. Santucci RA, Joyce GF, Wise M. Male urethral stricture disease. J Urol. 2007;177(5):1667-1674. doi:10.1016/j.juro.2007.01.041

2. Tritschler S, Roosen A, Füllhase C, Stief CG, Rübben H. Urethral stricture: etiology, investigation and treatments. Dtsch Arztebl Int. 2013;110(13):220-226. doi:10.3238/arztebl.2013.0220

3. Hampson LA, McAninch JW, Breyer BN. Male urethral strictures and their management. Nat Rev Urol. 2014;11(1):43-50. doi:10.1038/ nrurol.2013.275

4. Mundy AR, Andrich DE. Urethral strictures. BJU Int. 2011;107 (1):6-26. doi:10.1111/j.1464-410X.2010.09800.x

5. Zaid UB, Lavien G, Peterson AC. Management of the recurrent male urethral stricture. Curr Urol Rep. 2016;17(4):33. doi:10.1007/s11934016-0588-0

6. Verla W, Oosterlinck W, Spinoit AF, Waterloos M. A comprehensive review emphasizing anatomy, etiology, diagnosis, and treatment of male urethral stricture disease. Biomed Res Int. 2019;2019:9046430. doi: $10.1155 / 2019 / 9046430$

7. Lumen N, Hoebeke P, Willemsen P, De Troyer B, Pieters R, Oosterlinck W. Etiology of urethral stricture disease in the 21st century. J Urol. 2009;182(3):983-987. doi:10.1016/j.juro.2009.05.023

8. Wessells H, Morey AF, McAninch JW. Obliterative vesicourethral strictures following radical prostatectomy for prostate cancer: reconstructive armamentarium. $J$ Urol. 1998;160(4):1373-1375. doi:10.1016/S0022-5347(01)62540-0

9. Pansadoro V, Emiliozzi P. Internal urethrotomy in the management of anterior urethral strictures: long-term followup. J Urol. 1996;156 (1):73-75. doi:10.1016/S0022-5347(01)65942-1

10. Jasionowska S, Brunckhorst O, Rees RW, Muneer A, Ahmed K. Redo-urethroplasty for the management of recurrent urethral strictures in males: a systematic review. World J Urol. 2019;37 (9):1801-1815. doi:10.1007/s00345-019-02709-7
11. Sukumar S, Elliott SP, Myers JB, et al. Multi-institutional outcomes of endoscopic management of stricture recurrence after bulbar urethroplasty. $J$ Urol. 2018;200(4):837-842. doi:10.1016/j. juro.2018.04.081

12. Shaw NM, Venkatesan K. Endoscopic management of urethral stricture: review and practice algorithm for management of male urethral stricture disease. Curr Urol Rep. 2018;19(3):19. doi:10.1007/s11934018-0771-6

13. Heyns CF, Steenkamp JW, De Kock ML, Whitaker P. Treatment of male urethral strictures: is repeated dilation or internal urethrotomy useful? J Urol. 1998;160(2):356-358. doi:10.1016/s0022-5347(01)62894-5

14. Santucci R, Eisenberg L. Urethrotomy has a much lower success rate than previously reported. J Urol. 2010;183(5):1859-1862. doi:10.1016/j.juro.2010.01.020

15. Breyer BN, McAninch JW, Whitson JM, et al. Multivariate analysis of risk factors for long-term urethroplasty outcome. J Urol. 2010;183 (2):613-617. doi:10.1016/j.juro.2009.10.018

16. Zhivov AV, Tedeev RL, Koshmelev AA, Karpovich AV, Yudovskyi SO, Pushkar DY. [Results of treatment and risk factors for recurrence of iatrogenic urethral strictures in men]. Urologiia. 2019;5:7-13. Russian doi:10.18565/urology.2019.5.7-13

17. Duel BP, Barthold JS, Gonzalez R. Management of urethral strictures after hypospadias repair. J Urol. 1998;160(1):170-171. doi:10.1016/ S0022-5347(01)63083-0

18. Belsante MJ, Selph JP, Peterson AC. The contemporary management of urethral strictures in men resulting from lichen sclerosus. Transl Androl Urol. 2015;4(1):22-28. doi:10.3978/j.issn.2223-4683.2015.01.08

19. Kahokehr AA, Granieri MA, Webster GD, Peterson AC. A critical analysis of bulbar urethroplasty stricture recurrence: characteristics and management. J Urol. 2018;200(6):1302-1307. doi:10.1016/j. juro.2018.07.036

20. Barbagli G, Montorsi F, Balò S, et al. Treatments of 1242 bulbar urethral strictures: multivariable statistical analysis of results. World J Urol. 2019;37:1165-1171. doi:10.1007/s00345-018-2481-6

21. Rosenbaum CM, Schmid M, Ludwig TA, et al. Internal urethrotomy in patients with recurrent urethral stricture after buccal mucosa graft urethroplasty. World J Urol. 2015;33(9):1337-1344. doi:10.1007/ s00345-014-1450-y

22. Benson CR, Li G, Brandes SB. Long term outcomes of one-stage augmentation anterior urethroplasty: a systematic review and meta-analysis. Int Braz J Urol. 2021;47(2):237-250. doi:10.1590/ s1677-5538.ibju.2020.0242

23. Kulkarni SB, Joshi PM, Venkatesan K. Management of panurethral stricture disease in India. $J$ Urol. 2012;188(3):824-830. doi:10.1016/ j.juro.2012.05.020

24. Zumstein V, Dahlem R, Kluth LA, et al. A critical outcome analysis of Asopa single-stage dorsal inlay substitution urethroplasty for penile urethral stricture. World J Urol. 2020;38(5):1283-1294. doi:10.1007/s00345-019-02871-y

25. Ali AI, Hamid AA, Abdel-Rassoul MA, et al. Buccal mucosal graft versus penile skin flap urethroplasty for long segment penile urethral stricture: a prospective randomized study. Cent Eur J Urol. 2019;72 (2):191-197. doi:10.5173/ceju.2019.1899

26. Hmida W, Othmen MB, Bako A, Jaidane M, Mosbah F. Penile skin flap: a versatile substitute for anterior urethral stricture. Int Braz J Urol. 2019;45(5):1057-1063. doi:10.1590/s1677-5538.ibju.2018.0652

27. Godley SP, Sturm RM, Durbin-Johnson B, Kurzrock EA. Meatal stenosis: a retrospective analysis of over 4000 patients. $J$ Pediatr Urol. 2015;11(1):38.e1-6. doi:10.1016/j.jpurol.2014.09.006

28. Goel A, Goel A, Dalela D, Sankhwar,SN. Meatoplasty using double buccal mucosal graft technique. Int Urol Nephrol. 2009;41 (4):885-887. doi:10.1007/s11255-009-9555-8

29. Friel BJ, Skokan AJ, Kovell RC. Historical and current practices in the management of fossa navicularis strictures. Curr Urol Rep. 2019;20(6):30. doi:10.1007/s11934-019-0897-1 
30. Zumstein V, Dahlem R, Maurer V, et al. Single-stage buccal mucosal graft urethroplasty for meatal stenoses and fossa navicularis strictures: a monocentric outcome analysis and literature review on alternative treatment options. World J Urol. 2020;38(10):2609-2620. doi:10.1007/s00345-019-03035-8

31. Meeks JJ, Barbagli G, Mehdiratta N, Granieri MA, Gonzalez CM. Distal urethroplasty for isolated fossa navicularis and meata strictures. BJU Int. 2012;109(4):616-619. doi:10.1111/j.1464410X.2011.10248.x

32. Meeks JJ, Erickson BA, Granieri MA, Gonzalez CM. Stricture recurrence after urethroplasty: a systematic review. J Urol. 2009;182 (4):1266-1270. doi:10.1016/j.juro.2009.06.027

33. Erickson BA, Ghareeb GM. Definition of successful treatment and optimal follow-up after urethral reconstruction for urethral stricture disease. Urol Clin North Am. 2017;44(1):1-9. doi:10.1016/j. ucl.2016.08.001

34. Yeung LL, Brandes SB. Urethroplasty practice and surveillance patterns: a survey of reconstructive urologists. Urology. 2013;82 (2):471-475. doi:10.1016/j.urology.2013.03.069

35. Seibold J, Werther M, Alloussi S, et al. Urethral ultrasound as a screening tool for stricture recurrence after oral mucosa graft urethroplasty. Urology. 2011;78(3):696-700. doi:10.1016/j. urology.2011.04.051

36. Angermeier KW, Rourke KF, Dubey D, Forsyth RJ, Gonzalez CM. SIU/ICUD consultation on urethral strictures: evaluation and follow-up. Urology. 2014;83(3 Suppl):S8-17. doi:10.1016/j. urology.2013.09.011

37. Smith JC. Urethral resistance to micturition. $B r J$ Urol. 1968;40 (2):125-156. doi:10.1111/j.1464-410x.1968.tb09868.x

38. Erickson BA, Elliott SP, Voelzke BB, et al. Multi-institutional 1-year bulbar urethroplasty outcomes using a standardized prospective cystoscopic follow-up protocol. Urology. 2014;84(1):213-216. doi:10.1016/j.urology.2014.01.054

39. Erickson BA, Breyer BN, McAninch JW. The use of uroflowmetry to diagnose recurrent stricture after urethral reconstructive surgery. J Urol. 2010;184(4):1386-1390. doi:10.1016/j.juro.2010.06.015

40. Kessler TM, Fisch M, Heitz M, Olianas R, Schreiter F. Patient satisfaction with the outcome of surgery for urethral stricture. $J$ Urol. 2002;167(6):2507-2511. doi:10.1016/S0022-5347(05)65015-X

41. Morey AF, McAninch JW. [Therapy of urethral stricture using free transplants]. Therapie der Harnröhrenstriktur unter Verwendung freier Transplantate. Urologe A. 1998;37(1):38-41. German. doi:10.1007/s001200050146

42. Murphy GP, Fergus KB, Gaither TW, et al. Urinary and sexual function after perineal urethrostomy for urethral stricture disease: an analysis from the TURNS. J Urol. 2019;201(5):956-961. doi:10.1097/JU.0000000000000027

43. Jackson MJ, Sciberras J, Mangera A, et al. Defining a patient-reported outcome measure for urethral stricture surgery. Eur Urol. 2011;60(1):60-68. doi:10.1016/j.eururo.2011.03.003

44. Baradaran N, Hampson LA, Edwards TC, Voelzke BB, Breyer BN. Patient-reported outcome measures in urethral reconstruction. Curr Urol Rep. 2018;19(7):48. doi:10.1007/s11934-018-0797-9

45. Bertrand LA, Voelzke BB, Elliott SP, et al. Measuring and predicting patient dissatisfaction after anterior urethroplasty using patient reported outcomes measures. $J$ Urol. 2016;196(2):453-461. doi:10.1016/j.juro.2016.01.117

46. Breyer BN, Edwards TC, Patrick DL, Voelzke BB. Comprehensive qualitative assessment of urethral stricture disease: toward the development of a patient centered outcome measure. J Urol. 2017;198 (5):1113-1118. doi:10.1016/j.juro.2017.05.077

47. Goulao B, Carnell S, Shen J, et al. Surgical treatment for recurrent bulbar urethral stricture: a randomised open-label superiority trial of open urethroplasty versus endoscopic urethrotomy (the OPEN trial). Eur Urol. 2020;78(4):572-580. doi:10.1016/j.eururo.2020.06.003
48. Wessells H, Angermeier KW, Elliott S, et al. Male urethral stricture: American urological association guideline. J Urol. 2017;197 (1):182-190. doi:10.1016/j.juro.2016.07.087

49. Ekerhult TO, Lindqvist K, Peeker R, Grenabo L. Outcomes of reintervention after failed urethroplasty. Scand J Urol. 2017;51(1):68-72. doi:10.1080/21681805.2016.1264995

50. Brown ET, Mock S, Dmochowski R, Reynolds WS, Milam D, Kaufman MR. Direct visual internal urethrotomy for isolated, post-urethroplasty strictures: a retrospective analysis. Ther $A d v$ Urol. 2017;9(2):39-44. doi:10.1177/1756287216679946

51. Zhao LC, Hudak SJ, Morey AF. Reconstruction of traumatic and reoperative anterior urethral strictures via excisional techniques. Urol Clin North Am. 2013;40(3):403-406. doi:10.1016/j.ucl.2013.04.011

52. Snyder CL, Evangelidis A, Hansen G, et al. Management of complications after hypospadias repair. Urology. 2005;65(4):782-785. doi:10.1016/j.urology.2004.11.037

53. Siegel JA, Panda A, Tausch TJ, Meissner M, Klein A, Morey AF. Repeat excision and primary anastomotic urethroplasty for salvage of recurrent bulbar urethral stricture. J Urol. 2015;194(5):1316-1322. doi:10.1016/j.juro.2015.05.079

54. Kuo TL, Venugopal S, Inman RD, Chapple CR. Surgical tips and tricks during urethroplasty for bulbar urethral strictures focusing on accurate localisation of the stricture: results from a tertiary centre. Eur Urol. 2015;67(4):764-770. doi:10.1016/j.eururo.2014.12.029

55. Gelman J, Siegel JA. Ventral and dorsal buccal grafting for 1-stage repair of complex anterior urethral strictures. Urology. 2014;83 (6):1418-1422. doi:10.1016/j.urology.2014.01.024

56. Chowdhury PS, Nayak P, Mallick S, Gurumurthy S, David D, Mossadeq A. Single stage ventral onlay buccal mucosal graft urethroplasty for navicular fossa strictures. Indian J Urol. 2014;30 (1):17-22. doi:10.4103/0970-1591.124200

57. Blaschko SD, McAninch JW, Myers JB, Schlomer BJ, Breyer BN. Repeat urethroplasty after failed urethral reconstruction: outcome analysis of 130 patients. J Urol. 2012;188(6):2260-2264. doi:10.1016/j.juro.2012.07.101

58. Pfalzgraf D, Kluth L, Reiss P, Fisch M, Dahlem R. Redourethroplasty: comparison of early functional results and quality of life in penile and bulbar strictures. World $J$ Urol. 2014;32 (5):1191-1197. doi:10.1007/s00345-013-1182-4

59. Vetterlein MW, Stahlberg J, Zumstein V, et al. The impact of surgical sequence on stricture recurrence after anterior 1-stage buccal mucosal graft urethroplasty: comparative effectiveness of initial, repeat and secondary procedures. J Urol. 2018;200(6):1308-1314. doi:10.1016/j. juro.2018.06.067

60. Wessells H, McAninch JW. Current controversies in anterior urethral stricture repair: free-graft versus pedicled skin-flap reconstruction. World J Urol. 1998;16(3):175-180. doi:10.1007/s003450050048

61. Morey AF, Duckett CP, McAninch JW. Failed anterior urethroplasty: guidelines for reconstruction. J Urol. 1997;158(4):1383-1387. doi:10.1016/s0022-5347(01)64221-6

62. Cotter KJ, Hahn AE, Voelzke BB, et al. Trends in urethral stricture disease etiology and urethroplasty technique from a multi-institutional surgical outcomes research group. Urology. 2019;130:167-174. doi:10.1016/j.urology.2019.01.046

63. Morey AF, Watkin N, Shenfeld O, Eltahawy E, Giudice C. SIU/ ICUD consultation on urethral strictures: anterior urethra-primary anastomosis. Urology. 2014;83(3 Suppl):S23-6. doi:10.1016/j. urology.2013.11.007

64. Dubey D, Kumar A, Mandhani A, Srivastava A, Kapoor R, Bhandari M. Buccal mucosal urethroplasty: a versatile technique for all urethral segments. BJU Int. 2005;95(4):625-629. doi:10.1111/ j.1464-410X.2005.05352.x

65. Joseph JV, Andrich DE, Leach CJ, Mundy AR. Urethroplasty for refractory anterior urethral stricture. J Urol. 2002;167(1):127-129. doi:10.1016/S0022-5347(05)65396-7 
66. Goel A, Jain A, Singh BP. Management of panurethral strictures. Indian J Urol. 2011;27(3):378-384. doi:10.4103/0970-1591.85443

67. Browne BM, Vanni AJ. Use of alternative techniques and grafts in urethroplasty. Urol Clin North Am. 2017;44(1):127-140. doi:10.1016/j.ucl.2016.08.003

68. Manoj B, Sanjeev N, Pandurang PN, Jaideep M, Ravi M. Postauricular skin as an alternative to oral mucosa for anterior onlay graft urethroplasty: a preliminary experience in patients with oral mucosa changes. Urology. 2009;74(2):345-348. doi:10.1016/j. urology.2009.02.065

69. Nitkunan T, Johal N, O’Malley K, Cuckow P. Secondary hypospadias repair in two stages. J Pediatr Urol. 2006;2(6):559-563. doi:10.1016/ j.jpurol.2006.01.009

70. Chen ML, Odom BD, Johnson LJ, Santucci RA. Combining ventral buccal mucosal graft onlay and dorsal full thickness skin graft inlay decreases failure rates in long bulbar strictures $(\geq 6 \mathrm{~cm})$. Urology. 2013;81(4):899-902. doi:10.1016/j.urology.2012.11.055

71. Liu JS, Dong C, Gonzalez CM. Risk factors and timing of early stricture recurrence after urethroplasty. Urology. 2016;95:202-207. doi:10.1016/j.urology.2016.04.033

72. Dalpiaz O, Kerschbaumer A, Pelzer A, et al. Single-stage dorsal inlay split-skin graft for salvage anterior urethral reconstruction. BJU Int. 2008;101(12):1565-1570. doi:10.1111/j.1464-410X.2007.07436.x

73. Lanciotti M, Betti M, Elia A, et al. Proximal hypospadias repair with bladder mucosal graft: our 10 years experience. J Pediatr Urol. 2017;13(3):294.e1-294.e6. doi:10.1016/j.jpurol.2017.01.011

74. Wang Z, Zeng X, Chen R, et al. Free bladder mucosa graft harvested by water-jet: a novel, minimally invasive technique for urethral reconstruction. Exp Ther Med. 2018;16(3):2251-2256. doi:10.3892/ etm.2018.6469

75. Kinkead TM, Borzi PA, Duffy PG, Ransley PG. Long-term followup of bladder mucosa graft for male urethral reconstruction. $J$ Urol. 1994;151(4):1056-1058. doi:10.1016/s0022-5347(17)35179-0

76. Xu YM, Qiao Y, Sa YL, et al. 1-stage urethral reconstruction using colonic mucosa graft for the treatment of a long complex urethral stricture. $J$ Urol. 2004;171(1):220-223. doi:10.1097/01. ju.0000094810.60093.bc

77. Palmer DA, Marcello PW, Zinman LN, Vanni AJ. Urethral reconstruction with rectal mucosa graft onlay: a novel, minimally invasive technique. $J$ Urol. 2016;196(3):782-786. doi:10.1016/j. juro.2016.03.002

78. Scott KA, Li G, Manwaring J, et al. Liquid buccal mucosa graft endoscopic urethroplasty: a validation animal study. World J Urol. 2020;38(9):2139-2145. doi:10.1007/s00345-019-02840-5

79. Vaddi SP, Reddy VB, Abraham SJ. Buccal epithelium expanded and encapsulated in scaffold-hybrid approach to urethral stricture (BEES-HAUS) procedure: a novel cell therapy-based pilot study. Int J Urol. 2019;26(2):253-257. doi:10.1111/iju.13852

80. Mangir N, Wilson KJ, Osman NI, Chapple CR. Current state of urethral tissue engineering. Curr Opin Urol. 2019;29(4):385-393. doi:10.1097/mou.0000000000000637

81. De Filippo RE, Kornitzer BS, Yoo JJ, Atala A. Penile urethra replacement with autologous cell-seeded tubularized collagen matrices. J Tissue Eng Regen Med. 2015;9(3):257-264. doi:10.1002/term.1647

82. Fuehner C, Dahlem R, Fisch M, Vetterlein MW. Update on managing anterior urethral strictures. Indian $J$ Urol. 2019;35(2):94-100. doi:10.4103/iju.IJU_52_19
83. Buckley JC, Heyns C, Gilling P, Carney J. SIU/ICUD consultation on urethral strictures: dilation, internal urethrotomy, and stenting of male anterior urethral strictures. Urology. 2014;83(3 Suppl):S18-22. doi:10.1016/j.urology.2013.08.075

84. Potts BA, Belsante MJ, Peterson AC. Intraurethral steroids are a safe and effective treatment for stricture disease in patients with biopsy proven lichen sclerosus. J Urol. 2016;195(6):1790-1796. doi:10.1016/j.juro.2015.12.067

85. Barbagli G, De Angelis M, Romano G, Lazzeri M. Clinical outcome and quality of life assessment in patients treated with perineal urethrostomy for anterior urethral stricture disease. J Urol. 2009;182 (2):548-557. doi:10.1016/j.juro.2009.04.012

86. McKibben MJ, Rozanski AT, Fuchs JS, Sundaram V, Morey AF. Versatile algorithmic midline approach to perineal urethrostomy for complex urethral strictures. World J Urol. 2019;37(7):1403-1408. doi:10.1007/s00345-018-2522-1

87. Peterson AC, Palminteri E, Lazzeri M, Guanzoni G, Barbagli G, Webster GD. Heroic measures may not always be justified in extensive urethral stricture due to lichen sclerosus (balanitis xerotica obliterans). Urology. 2004;64(3):565-568. doi:10.1016/j. urology.2004.04.035

88. Hiradfar M, Shojaeian R, Sharifabad PS. Two staged modified substitution urethroplasty using appendix-free flap. BMJ Case Rep. 2015;2015:bcr2015210771. doi:10.1136/bcr-2015-210771

89. Bales GT, Kuznetsov DD, Kim HL, Gottlieb LJ. Urethral substitution using an intestinal free flap: a novel approach. J Urol. 2002;168 (1):182-184. doi:10.1016/S0022-5347(05)64857-4

90. Lee OT, Durbin-Johnson B, Kurzrock EA. Predictors of secondary surgery after hypospadias repair: a population based analysis of 5,000 patients. J Urol. 2013;190(1):251-255. doi:10.1016/j.juro.2013.01.091

91. Talab SS, Cambareri GM, Hanna MK. Outcome of surgical management of urethral stricture following hypospadias repair. $J$ Pediatr Urol. 2019;15(4):354.e1-354.e6. doi:10.1016/j.jpurol.2019.05.025

92. Barbagli G, De Angelis M, Palminteri E, Lazzeri M. Failed hypospadias repair presenting in adults. Eur Urol. 2006;49(5):887-894. doi:10.1016/j.eururo.2006.01.027

93. Barbagli G, Perovic S, Djinovic R, Sansalone S, Lazzeri M. Retrospective descriptive analysis of 1,176 patients with failed hypospadias repair. J Urol. 2010;183(1):207-211. doi:10.1016/j. juro.2009.08.153

94. Tang SH, Kao CC, Wu ST, Meng E, Cha TL. Inlay buccal mucosal graft for reoperative posterior urethroplasty. Kaohsiung $\mathrm{J} \mathrm{Med} \mathrm{Sci.}$ 2012;28(4):220-224. doi:10.1016/j.kjms.2011.10.024

95. Chung ASJ, Suarez OA. Current treatment of lichen sclerosus and stricture. World J Urol. 2020;38(12):3061-3067. doi:10.1007/ s00345-019-03030-Z

96. Venn SN, Mundy AR. Urethroplasty for balanitis xerotica obliterans. $\mathrm{Br}$ J Urol. 1998;81(5):735-737. doi:10.1046/j.1464-410x.1998.00634.x

97. Kulkarni S, Barbagli G, Kirpekar D, Mirri F, Lazzeri M. Lichen sclerosus of the male genitalia and urethra: surgical options and results in a multicenter international experience with 215 patients. Eur Urol. 2009;55(4):945-954. doi:10.1016/j.eururo.2008.07.046

98. Patel CK, Buckley JC, Zinman LN, Vanni AJ. Outcomes for management of lichen sclerosus urethral strictures by 3 different techniques. Urology. 2016;91:215-221. doi:10.1016/j.urology.2015.11.057

99. Granieri MA, Peterson AC, Madden-Fuentes RJ. Effect of lichen sclerosis on success of urethroplasty. Urol Clin North Am. 2017;44 (1):77-86. doi:10.1016/j.ucl.2016.08.004 


\section{Publish your work in this journal}

Research and Reports in Urology is an international, peer-reviewed, open access journal publishing original research, reports, editorials, reviews and commentaries on all aspects of adult and pediatric urology in the clinic and laboratory including the following topics: Pathology, pathophysiology of urological disease; Investigation and treatment of urological disease; Pharmacology of drugs used for the treatment of urological disease. The manuscript management system is completely online and includes a very quick and fair peer-review system, which is all easy to use. Visit http://www.dovepress.com/ testimonials.php to read real quotes from published authors.

Submit your manuscript here: https://www.dovepress.com/research-and-reports-in-urology-journal 